\title{
Magnetic Nanoparticles as Inductive Heating Elements in Microreactors
}

Polymer-Supported Synthesis

Key words

flowthrough reactor nanoparticles

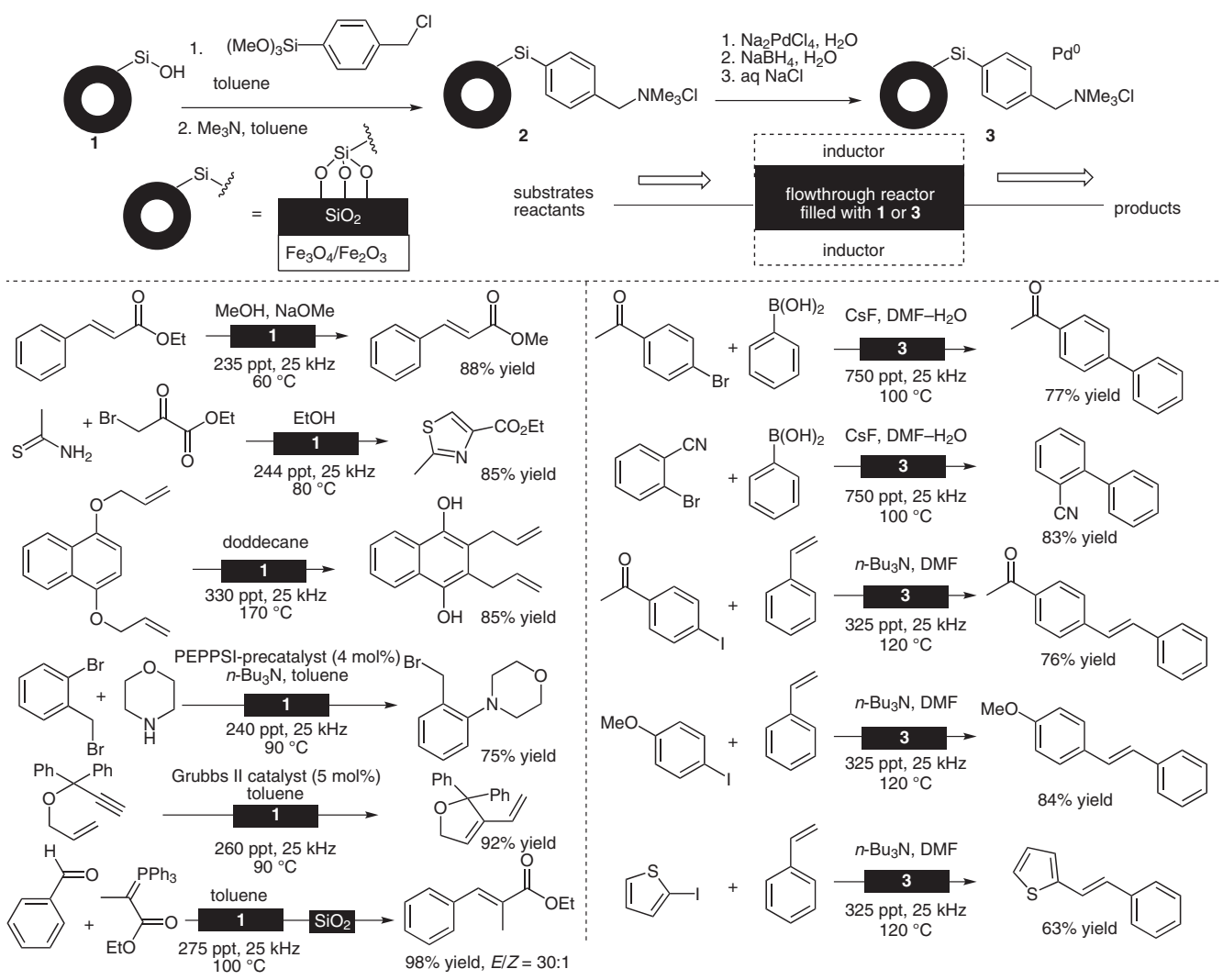

Significance: $\mathrm{SiO}_{2}$-coated magnetic nanoparticles 1 and $3\left(\mathrm{Fe}_{3} \mathrm{O}_{4} / \mathrm{Fe}_{2} \mathrm{O}_{3}\right.$ nanoparticles) were developed as heating elements for organic reactions, which were self-heated in an electromagnetic field. Thus, a microflow reactor $(14 \mathrm{~cm}$ long, $\varnothing 9 \mathrm{~mm}$ ) was filled with a mixture of magnetic nanoparticles 1 and sand (3:1, $5.5 \mathrm{~g})$ without/with $400 \mathrm{mg}$ of Pd-doped material 3 (2.8 mol\%, 0.028 $\mathrm{mmol} \mathrm{Pd}$ ). The trans-esterification, Claisen rearrangement, the Buchwald-Hartwig amination, enyne metathesis and Wittig reaction were performed with $\mathbf{1}$ in an electromagnetic field under continuous-flow conditions to give the corresponding products in 75-98\% yield (6 examples).
Comment: The Suzuki-Miyaura and Heck reactions were also carried out with Pd-doped magnetic nanoparticles $\mathbf{3}$ to afford the corresponding coupling products in 63-84\% yield (five examples). The silica-coated $\mathrm{Fe}_{3} \mathrm{O}_{4} / \mathrm{Fe}_{2} \mathrm{O}_{3}$ magnetic nanoparticles $\mathbf{1}$ were prepared according to the reported procedure (M. R. Zachariah and coworkers Nanostruct. Mater. 1995, 5, 383; S. H. Ehrman et al. J. Mater. Res. 1999, 14, 4551). 